\title{
Snakes and Ladders: Lessons From Pacific Health Promotion
}

\author{
Malakai Ofanoa $^{a}$, Teuila Percivala, Peter Huggard ${ }^{a}$, Stephen Buetow ${ }^{a}$
}

\begin{abstract}
This paper focuses on health promotion and community development programmes conducted within Pacific nation locations. A literature review was carried out that identified differences in understanding of the practice of health promotion and community development in Pacific Island communities when compared with the rest of the developed world: Snakes and ladders is a metaphor for process and progress of such programmes whereby health and community gains are made only to collapse and fall back, close to or at, the starting point. Reasons for this are discussed, particularly through comparison with health promotion and community development programmes in other non-Pacific countries, and with success factors identified in such programmes. This link between methodological approaches of international funding agencies and the success or otherwise of programmes, is identified. Suggestions are made as to approaches to be used when working within Pacific Island nations. These approaches involve empowerment of the local community to lead, manage, and evaluate the effectiveness of these health promotion and community development programmes.
\end{abstract}

\section{Keywords}

Pasifika, empowerment, health promotion, community development

The world is facing health dilemmas of growing complexity owing to factors such as global warming, world poverty, and most recently, the economic crisis that struck every nation in 2008 (Ofanoa 2010). Such factors and crises are multi-dimensional, and a variety of social, economic, political, health, and cultural approaches are required to alleviate them. Health leaders in New Zealand and the Pacific region must have theoretical and practical discussions today, not only about the multiple determinants of the health and well-being of Pacific peoples but more so about the solutions needed to redress these issues through appropriate and effective Pacific health promotion and community development programmes.

A recent review of the public health literature (Ofanoa 2010) revealed that many of these programmes can be described metaphorically as games of "snakes and ladders". Some programmes successfully climb up the ladder of success within a short period of time but, bitten by the snakes of challenges, then suddenly collapsed and failed to recover. They are back to square one. However, it is unacceptable for Pacific health promotion and community development approaches to be games of chance. While snakes lurk always around the corner, steps can be taken to evade them in order to reach the ladders that exist for all snakes. Fidelity to this belief invites questions about the types of programmes used

aUniversity of Auckland, New Zealand

\section{Correspondent Author:}

Malakai Ofanoa, 269 Morrin Rd, School of Population Health, University o Auckland, Auckland, New Zealand

E-mail: m.ofanoa@auckland.ac.nz 
by Pacific health providers and practitioners in the Pacific region including New Zealand. How can these programmes be improved by going beyond traditional top-down health promotion approaches that victimise and blame populations (Laverack 2004; Ofanoa 2010)? Pacific people need cogent answers to such questions to improve their health and well-being (Ofanoa 2010).

This paper therefore reviews literature to highlight public health lessons learnt from critically examining the "snakes and ladder game" played in Pacific health promotionand community development over the last decade (Ofanoa 2010). It further suggests some ways to revise and refine Pacific health promotion strategies to better meet current needs of Pacific peoples in the region and New Zealand.

\section{METHODOLOGY}

A non-systematic approach was taken to inform the search strategy for this review. The first steps involved formulating the research question, defining the scope of the review, and identifying the search terms.

The second set of steps comprised identifying library databases that hold key sources of information related to the study topic. The main databases searched were: Medline, The Cochrane Library, Stats New Zealand, Scopus, Science Direct, Google Scholar, and Google. The University of Auckland's online Library Catalogue (Voyager) was also searched. Hand searching was conducted of the Pacific Health Dialogue series and textbooks in the Pacific Health Section of the School of Population Health.

Also searched were grey literature databases such as Dissertation Abstracts and Index New Zealand. They revealed relevant government, non-government, and international agency reports and websites [e.g., from the New Zealand Ministry of Health, Ministry of Youth Development, Ministry of Pacific Island Affairs, World Health Organization (WHO), and
Centres for Disease Control and Prevention]. Lastly, reference lists of retrieved studies were examined to maximise the comprehensiveness of the search which was restricted to the period 1990-2012.

The key search terms included: community, public health, community development, empowerment, community action, social action, democracy, equity, equality, minority groups, health promotion, Ottawa Charter, Pacific people, Pasifika, capacity building. Through Boolean operators (“And" and "Or”), these terms were generally combined with: Prevention and/or Management, New Zealand and Pacific and/or Maori. Sixty relevant works were retrieved.

\section{FINDINGS}

This section discusses the findings from the literature review. It shows evidence of continuing differences and gaps between how health promotion and community development are understood and implemented in the Pacific Island countries compared with the rest of the developed world. In the Pacific countries, a "snakes and ladder game" has continued to characterize health promotion and community development activity over the last decade. Meanwhile, the understanding of, and approaches taken for health promotions elsewhere in the developed world have advanced dramatically. Health promotion there has come to focus on "empowering approaches" that enable people to increase control over the conditions affecting their lives (Labonte 1998). These approaches embrace key values like empowerment (Nutbeam 1998; Raeburn and Rootman 1998; Laverack 2004), social justice and equity (Health Canada 1998), and respect (Nutbeam 1998). By contrast, in the Pacific, the donor agencies still control and lead health promotion programs.

Further, the literature identified two main health promotion domains. One is "policy-centred", the other is "people-centred" (Raeburn 2001). The policy domain signifies the "macro-dimension" of health 
promotion. Raeburn (2005) described it as like taking "an Olympian view of the world, of a nation, of a community and of a whole population, and attempting to create healthy public policies to direct global, regional, national and local health authorities to create changes on the social determinants of health of the world and the various communities". This domain best characterizes health promotion activities in Pacific Island countries. These countries are driven and supported to deal with issues relating to globalisation and public health (Beaglehole 2003), while their own felt needs are way back in their list of priorities.

In contrast, the "people-centred health promotion domain" retains or restores focus on the people by acknowledging the importance of "meso- and micro-dimensions" of health promotion (Raeburn 2005). At the meso-level, the community is the focus, while the micro-level empowers the individual, small group or family as people in their natural environment. People are seen as active decision makers who are capable of helping to meet their own needs (Raeburn 2005). When people feel in control of their own lives, their health is enhanced and they feel very strong (Sarafino 1998). This thesis is that this domain is the most appropriate for community development in Pacific Island countries.

People-centred health promotion has long been practised in developing countries by international aid agencies and in social and economic development projects worldwide (Berkowitz 1984). Indeed, with the support of WHO, community development has been commonly defined as: "A people-centred approach that aims to develop the social, economic, environmental and cultural wellbeing of communities with a particular focus on marginalized members. It has a participatory emphasis on identifying solutions to community problems based on local knowledge and priorities” (Herman, Saxena, and Moodie 2004).

Community development of this nature promotes social cohesion (Florin and Wandersman 1990; Rapp
1998). It encourages community participation and involvement (Minkler 1990). It serves as a therapeutic force to prevent anti-social behaviours, and it can mitigate and prevent social determinants like unemployment, crime, poverty, and illness (Minkler 1990). There is no question for us that the "people-centred approach" should be the main thrust of any health promotion and community development activities conducted in Pacific countries.

Here are some examples of effective community development and health promotion projects documented worldwide and in New Zealand that employed the "people-centred approaches". The KHOJ Projects organised by the Voluntary Health Association of India (Mukhopadhyay 2004) reported success in health development and building the capacity of hundreds of poor and socioeconomically undeveloped communities in India from 1993 to 2003. The project brought holistic change to the lives of disadvantaged Indians through community empowerment, community mobilisation, capacity building, partnership and cooperation for health. The KHOJ Project managed to redress issues of poverty, health, housing, and sanitation in different parts of India. KHOJ is a Hindi word, which literally means "search".

There is evidence from Latin America, of the success of community development projects to address issues related to poverty and socio-economic disparities. Here success is based on the community capacity building initiatives to ensure all community development projects address issues related to the priority needs and wants of Latin Americans (Restrepo 2000).

In Lima's El Salvador, for example, ordinary Peruvians were able to reduce illiteracy by $3 \%$ and the infant mortality rate to $40 \%$ below the national average (Restrepo 2000). The latter rate is now one of the lowest rates in Latin America. The primary reason was the development of a community capacity building strategy and a democratic administrative 
structure to facilitate local community initiatives. Thus, women's organisations and the neighbourhood associations within the country now work together and collaborate with each other.

In Honduras in 2004, the government and the Ministry of Health were similarly able to enhance health and wellbeing in poor and isolated rural communities, through community-initiated actions and capacity building, as integral components of community development (Raeburn 2001).

In New Zealand, a developed country with a sizeable Pacific community, the success of the community house project in North Shore, Auckland exemplifies the effectiveness of community development approaches for Pacific health promotion. It still survives after 30 years. This project uses a simple community-controlled organisational approach called the PEOPLE System Model (Raeburn and Rootman 1998). This model incorporates a step-by-step system of needs assessment, planning, organisation, implementation, and evaluation of the project.

\section{SNAKES AND LADDER GAMES IN PACIFIC ISLAND COUNTRIES}

A stocktake of work experiences (from 1981 to 1998), plus continual observation of, and reflection on, health promotion programs development and approaches in the Pacific region, shows that empowerment approaches and strategies look good theoretically, but are difficult to implement in practice. International donor agencies with health interests in the region still control and manage most programs. These agencies control the financial resources and knowhow needed to change behaviour among Pacific people and their communities in the region. They still prescribe programs to develop on the basis of their own priorities, timeframes and what they want done, implemented and evaluated. This problem undermines health promotion development and strategies to control lifestyle diseases in the region. Unfortunately, the Pacific population is only involved in the implementation of programs and activities that targets their own specific health issues and interests in the region. They are not empowered to take the lead in managing determinants of their health and wellbeing. It is no wonder therefore that most programmes climb the ladder of success within a short period but, bitten by the snakes of policy challenges, then suddenly collapse and never recover.

\section{DISCUSSION}

Pacific people need to be empowered to lead, own, manage, and control the determinants of their health and wellbeing in New Zealand and the Pacific region. Whilst in practice, developed countries are taking people-centred approach to health promotion that is not the case in Pacific countries. Significant progress will not take place until Pacific people can freely identify and act on their own needs (Raeburn and Rootman 1998). This bottom-up approach is the best option for them to use in the region and in New Zealand, because it enables them to take control over to improve their health, wellbeing, and quality of life rather than illness and diseases (Raeburn and Rootman 1998), and is in accord with the Ottawa Charter (World Health Organization [WHO] 1986). Moreover, the approach is culturally appropriate for Pacific people. It aligns with their cultural values that include collectivity, social relationship, spirituality, reciprocity, respect, caring and sharing, cooperation, oneness and connectedness. It thereby promotes Pacific cultures and ways of living in their communities, family, kainga, and whanau. It helps to develop a sense of community and community cohesion by promoting key community concepts like: community capacity building, community mobilisation, integration, empowerment, community control, meaningful engagement, and community participation. 
For these reasons, Pacific people themselves would be responsive to policy to use people-centred health promotion to alleviate the determinants of their health and well-being if they are enabled to do so.

\section{CONCLUSIONS}

While Pacific people themselves have acknowledged Pacific health promotion in the past, there is a need to empower Pacific health leaders, public health and health promotion practitioners and Pacific communities for positive change. Pacific health promotion and community development activities still focus on health education rather than encompass a broader health promotion approach (Laverack 2004; Ofanoa 2010).

Many of them are funded by government or non-governmental agencies employing top down rational approaches and targeted knowledge and individual behavioural change. They still use professionally designed and led social marketing; communication and mass media campaigns without addressing community needs and the determinants of health and well-being. The agencies tend to implement large scale programmes within a very short timeframe, with most health promotion and community development activities still focusing on disease and ill health and with less focus on the holistic people-centered model that has been adopted and practised successfully in other health systems over the past decades.

Positive change will require empowering Pacific communities. Human resources capacity in health promotion in the Pacific and New Zealand is limited (Laverack 2007). Hence, health promotion practitioners require proper training and re-orientation. Anecdotal evidence has indicated that many Pacific (and other) health promoters are confused by the plethora of terms used synonymously with health promotion, such as: Information, Education and Communication (IEC), Strategic Health
Communication (SHC), and Behavioural Change Communication (BCC). Moreover, there is a lack of infrastructure, financial resources, research and evaluation skills and, healthy public policy, documentation to support Pacific health promotion programmes in the Pacific and New Zealand because they are not a priority. Change in structures and processes are urgently needed therefore to promote Pacific health.

A way forward for Pacific health promotion and community development in the region, and in New Zealand, is to:

(1) Review Pacific health promotion and community development activities in the Pacific and in New Zealand, and through scoping and evaluating them, to identify what works and does not work;

(2) Empower Pacific communities both in New Zealand and in the region to lead and take control over the determinants of their health and well-being through empowering social groups like churches, women's group, youth groups, men's groups, and other social groups in community development initiatives;

(3) Establish a Pacific centre of excellence in the region for the development, re-orientation, and training of Pacific health promoters at the undergraduate and postgraduate levels;

(4) Establish networks, partnerships, and alliances among Pacific governments, non-governmental agencies, universities, the Secretariat of Pacific Countries (SPC), the WHO, and other United Nations agencies. Such relationships may lead to greater collaboration and potential increases in funding for Pacific health promotion developmentsin the Pacific and New Zealand;

(5) Develop government policies that recognize health promotion as a priority as well as an integral component of all Pacific health developments in the Pacific region;

(6) Identify, allocate, and provide financial resources to support health promotion activities at the 
grassroots and communities;

(7) Re-orient and re-organise health promotion approaches to focus on the determinants of health especially the health and wellbeing needs of young children and youths in the Pacific and New Zealand;

(8) Research the role of social media, and social marketing approaches that will support community health promotion initiatives;

(9) That a theme like "Enabling All Pacific Children and Communities to Live Well” be a guiding principle in Pacific health promotion for the next century.

\section{References}

Beaglehole, R., ed. 2003. Global Public Health: A New Era. Oxford: Oxford University Press.

Berkowitz, B. 1984. Community Dreams. San Luis Obispo, CA: Impact.

Florin, P. and A. Wandersman. 1990. "An Introduction to Citizen Participation, Voluntary Organization and Community Development: Insights for Empowerment Through Research.” American Journal of Psychology 18(1):41-54.

Health Canada. 1998. Taking Action on Population Health: A Position Paper for Health Promotion and Programs Branch Staff. Ottawa, Canada: Author.

Herman, H., S. Saxena, and R. Moodie. 2004. Promoting Mental Health: Concepts, Emerging Evidence, Practice: Summary Report. Geneva: WHO.

Labonte, R. 1998. A Community Development Approach to Health Promotion. Edinburgh: Health Education Board of Scotland/Research Unit in Health and Behavioural Change.

Laverack, G. 2004. Health Promotion Practice: Power \& Empowerment. London: SAGE Publications.

- 2005. Public Health Practice: Power, Empowerment and Professional Practice. London: Sage Publications.

- 2007. Health Promotion Practice: Building Empowered Communities. London: McGraw-Hill.

Laverack, G. and N. Wallenstein. 2001. "Measuring Community Empowerment: A Fresh Look at Organizational Domains.” Health Promotion International 16:179-185.

Minkler, M. 1990. "Improving Health Through Community Organisation.” Pp. 257-287 in Health Behaviour and Health Education, edited by K. Glanz, F. M. Lewis, and B. K. Rimer. San Francisco: Jossey-Bass.

Mukhopadhyay, A. 2004. Khoj: A Search for Innovations and
Sustainability in Community Health and Development. New Delhi: Voluntary Health Association of India.

Nutbeam, D. 1998. "Evaluating Health Promotion: Progress, Problems and Solutions.” Health Promotion International 13(1):27-44.

Ofanoa, M. M. 2010. “Loto’i Tonga: A Community Development/Health Promotion Model for Tongans Living in Urban Areas." Unpublished, Doctor of Philosophy, University of Auckland.

Raeburn, J. 2001. “Communty Approaches to Mental Health Promotion.” International Journal of Mental Health Promotion 9(3):13-19.

—. 2005. "Community Capacity Building and Mobilization: Current Dimensions of Community Action in Health Promotion.” A Discussion Paper Presented at the Sixth Global Conference on Health Promotion, August 7-11, Bangkok.

Raeburn, J. and I. Rootman. 1989. “Towards an Expanded Health Field Concept: Conceptual Research Issues in a New Era of Health Promotion." Health Promotion 3(4):383-391.

—. 1998. People-Centred Health Promotion. Chichester: John Wiley \& Sons.

Raeburn, J. and R. Herd. 2003. Gambling and Public Health-A Work Plan. Auckland: The Problem Gambling Committee.

Raeburn, J. and S. MacFarlane. 2003. "Putting the Public Into Public Health: Towards a More People-Centred Approach.” In Global Public Health: A New Era, edited by R. Beaglehole. Oxford: Oxford University Press.

Rapp, C. A. 1998. Strengths Model: Case Management With People Suffering From Severe and Persistent Mental Illness. New York: Oxford University Press.

Sarafino, E. P. 1998. Health Psychology: Bio-Psychosocial Interactions. 3rd ed. New York: Wiley.

World Health Organization (WHO). 1986. "Ottawa Charter for Health Promotion." Canadian Journal of Public Health 77:6. Geneva, Switzerland.

\section{Bios}

Malakai Ofanoa, Ph.D., MHPSc, BHSc, ADHE., lecturer in Pacific health, School of Population Health, Faculty of Medical and Health Sciences, University of Auckland, New Zealand; research fields: health promotion, community development, social marketing, qualitative research, Pacific health, hepatitis $\mathrm{B}$, rheumatic fever, and stroke.

Teuila Percival, MBChB, FRACP, Head of Pacific Health Section, School of Population Health, Faculty of Medical and Health Sciences, University of Auckland, New Zealand; research fields: child health, maternal health, Pacific health, 
primary health care, disability, and adolescent/youth health.

Peter Huggard, EdD, MPH, Med, senior lecturer, School of Population Health, Faculty of Medical and Health Sciences, University of Auckland, New Zealand; research fields: stress, burnout, vicarious trauma, therapeutic communication, loss and grief, and Pacific health.
Stephen Buetow, Ph.D., associate professor, Department of General Practice and Primary Health Care, School of Population Health, Faculty of Medical and Health Sciences, University of Auckland, New Zealand; research fields: person-centred health care, social theory, and qualitative research. 